\title{
Significance of SGK1 as a Protein Kinase Transcriptionally Regulated by ALK1 Signaling in Vascular Endothelial Cells
}

\section{5}

\author{
Osamu Nakagawa, Yusuke Watanabe, Yukihiro Harada, \\ Toru Tanaka, and Teruhisa Kawamura
}

\section{Keywords}

Serum/glucocorticoid-regulated kinase 1 - AGC family kinases · ALK1 signaling · Endothelial transcription · Vascular development

Bone morphogenetic protein 9 (BMP9)/BMP10-ALK1 receptor signaling is essential for endothelial differentiation and vascular morphogenesis and is implicated in hereditary hemorrhagic telangiectasia and pulmonary arterial hypertension [1]. The ALK1 signal induces SMAD1/5/9-dependent transcription of its own signaling components, transcription factors and membrane ligands/receptors. In addition, we recently identified Serum/glucocorticoid-regulated kinase 1 (SGK1) to be transcriptionally regulated by ALK1 signaling in vascular endothelial cells [2] (Fig. 45.1a). The ALK1 signal is known to evoke post-translational activation of protein kinases such as TAK1 and ERK as a non-canonical pathway, but SGK1 is the first example of protein kinases whose expression is controlled by the SMAD-dependent pathway (Fig. 45.1b).

\footnotetext{
O. Nakagawa $(\bowtie) \cdot$ Y. Watanabe $\cdot$ T. Tanaka

Department of Molecular Physiology, National Cerebral and Cardiovascular Center Research Institute, Osaka, Japan

e-mail: osamu.nakagawa@ncvc.go.jp

Y. Harada

Department of Molecular Physiology, National Cerebral and Cardiovascular Center Research Institute, Osaka, Japan

Laboratory of Stem Cell and Regenerative Medicine, Department of Biomedical Sciences, College of Life Sciences, Ritsumeikan University, Shiga, Japan

T. Kawamura

Laboratory of Stem Cell and Regenerative Medicine, Department of Biomedical Sciences, College of Life Sciences, Ritsumeikan University, Shiga, Japan
} 

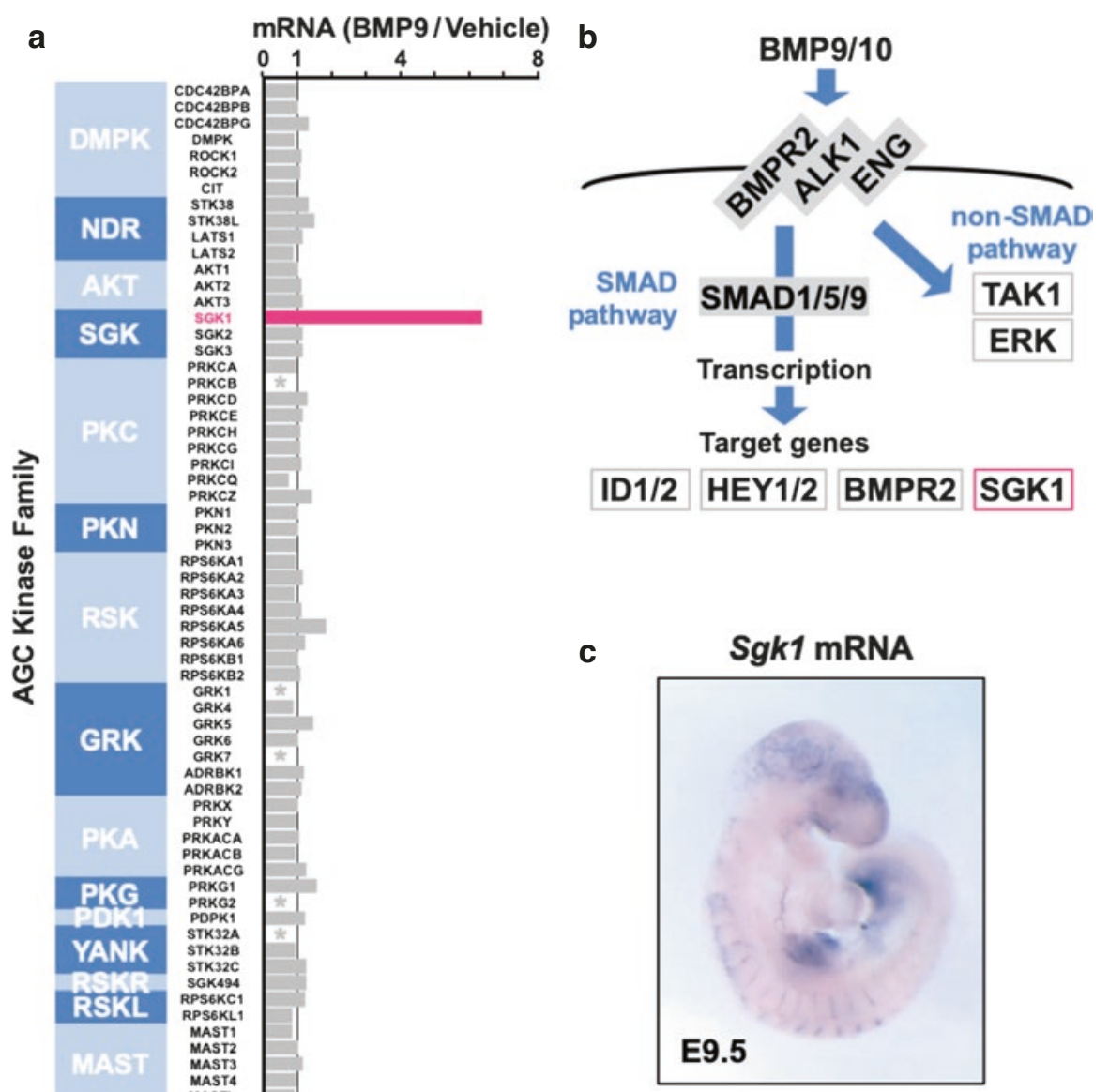

*: below detection limit

Fig. 45.1 (a) Specific induction of SGK1 mRNA expression by ALK1 signaling. Microarray results of the AGC family kinases using human umbilical artery endothelial cells at 2 hours after BMP9 stimulation $(10 \mathrm{ng} / \mathrm{mL})$ are shown. (b) A schematic of the SMAD-dependent and -independent pathways of ALK1 signaling and representative downstream targets. (c) Endothelial expression of $S g k 1$ mRNA during embryonic development. The in situ hybridization result of a mouse embryo (embryonic day 9.0) is shown

SGK1 belongs to the AGC (named after PKA, PKG and PKC) superfamily of protein kinases often involved in cardiovascular development and disease [3]. The microarray screen using BMP9-stimulated endothelial cells demonstrates that only SGK1 shows significant increase in mRNA expression among the AGC kinases (Fig. 45.1a). SGK1 plays pivotal roles in renal sodium reabsorption and T cell differentiation as well as cardiovascular diseases such as hypertension and cardiac arrhythmia [3]. Furthermore, $S g k 1$ null mice with a particular genetic background exhibit severe abnormalities of vascular development and embryonic lethality [4], suggesting its role in the mechanisms of angiogenesis defects due to ALK1 
signaling deficiency. While $S g k 1$ mRNA is clearly enriched in vascular endothelial cells of mouse embryos (Fig. 45.1c), nothing was known as to how its specific expression was achieved in vivo. It is important to identify an $S g k l$ endothelial enhancer and examine whether SMAD cooperates with endothelial transcription factors to control the $S g k l$ expression. Moreover, the expression and kinase activity of SGK1 are regulated not only by its transcription but also by mRNA turnover, protein degradation and phosphorylation. It will be of significance to clarify how SGK1 function is optimized in developing vasculature.

Acknowledgment This work was supported in part by the grants from the Ministry of Education, Culture, Sports, Science and Technology, the Smoking Research Foundation and the Novartis foundation (Japan).

\section{References}

1. Garcia de Vinuesa A, Abdelilah-Seyfried S, Knaus P, et al. BMP signaling in vascular biology and dysfunction. Cytokine Growth Factor Rev. 2016;27:65-79.

2. Araki M, Hisamitsu T, Kinugasa-Katayama Y, et al. Serum/glucocorticoid-regulated kinase 1 as a novel transcriptional target of bone morphogenetic protein-ALK1 receptor signaling in vascular endothelial cells. Angiogenesis. 2018;21:415-23.

3. Di Cristofano A. SGK1: the dark side of PI3K Signaling. Curr Top Dev Biol. 2017;123:49-71.

4. Catela C, Kratsios P, Hede M, et al. Serum and glucocorticoid-inducible kinase 1 (SGK1) is necessary for vascular remodeling during angiogenesis. Dev Dyn. 2010;239:2149-60.

Open Access This chapter is licensed under the terms of the Creative Commons Attribution 4.0 International License (http://creativecommons.org/licenses/by/4.0/), which permits use, sharing, adaptation, distribution and reproduction in any medium or format, as long as you give appropriate credit to the original author(s) and the source, provide a link to the Creative Commons license and indicate if changes were made.

The images or other third party material in this chapter are included in the chapter's Creative Commons license, unless indicated otherwise in a credit line to the material. If material is not included in the chapter's Creative Commons license and your intended use is not permitted by statutory regulation or exceeds the permitted use, you will need to obtain permission directly from the copyright holder.

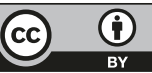

